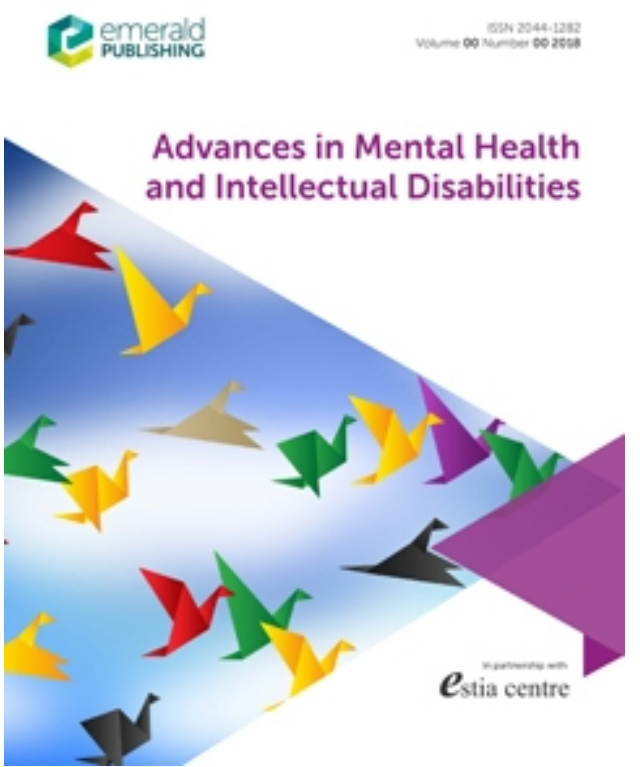

The prevention of offending behaviour by people with intellectual disabilities: a case for specialist childhood and adolescent early intervention?

\begin{tabular}{|r|l|}
\hline Journal: & Advances in Mental Health and Intellectual Disabilities \\
\hline Manuscript ID & AMHID-03-2019-0008.R1 \\
\hline Manuscript Type: & Research Paper \\
\hline Keywords: & $\begin{array}{l}\text { Learning disability, Development disability, Forensic, Youth, Secure, } \\
\text { HCR-20 }\end{array}$ \\
\hline \multicolumn{2}{l}{} \\
\hline
\end{tabular}




\title{
The prevention of offending behaviour by people with intellectual disabilities: a case for specialist childhood and adolescent early intervention?
}

\begin{abstract}
Introduction: Elucidating where antisocial or violent behaviour arises within the life course of individuals with intellectual disability (ID) could improve outcomes within this population, through informing services and interventions which prevent behaviours reaching a forensic threshold.
\end{abstract}

Method: The Historical Clinical Risk Management-20, Version 3 (HCR-20V3) assessments of a cohort of 84 inpatients within a forensic ID service were analysed for this study, with a particular emphasis on items concerned with the age at which antisocial or violence first emerged.

Results: For most participants, violent or antisocial behaviour was first observed in childhood or adolescence. The study also highlighted a smaller subgroup, whose problems with violence or antisocial behaviour were first observed in adulthood.

Discussion: The study findings suggest that targeted services in childhood and adolescence may have a role in reducing the offending behaviour and forensic involvement of people with ID. This has implications for the service models provided for children and adolescents with ID with challenging or offending behaviour.

\section{Keywords}

1. Learning disabilities

2. Developmental disabilities

3. Forensic

4. Secure

5. Youth

6. HCR-20 


\section{Introduction}

In the United Kingdom (UK), specialised forensic / secure services exist for individuals with an intellectual disability (ID) who have committed a criminal offence or exhibited behaviours which reach a forensic threshold. Such services care for people diverted from imprisonment due to their vulnerability (Talbot, 2009), and offer a multi-disciplinary model of support within an environment that emphasises treatment rather than punishment (Hollins, 2000). In recent years, a developing body of literature has focused on the sociodemographic, clinical, and forensic characteristics, and treatment outcomes of this group (Alexander et al., 2011). These studies have highlighted a high level of clinical complexity and associated forensic risk (Taylor, McKinnon, Thorpe, \& Gillmer, 2017).

Inpatient services for people with ID and mental health or behavioural problems in the UK have come under scrutiny as a result of an abuse scandal at Winterbourne View hospital, which was exposed by an investigative report broadcast on the television programme 'Panorama' in 2011 (BBC One, 2011). The resulting Transforming Care programme committed to a rapid reduction in the number of people with ID within inpatient care, including those in forensic services (Taylor, McKinnon, Thorpe, \& Gillmer, 2017). However, the dramatic subsequent reduction in hospital placements that was expected did not happen (Health and Social Care Information Centre, 2013). It is now acknowledged that the complexity and scale of the challenge was underestimated, and the scope and quality of data on inpatients with ID was poor (National Audit Office, 2015). A number of reasons have been suggested for the failure to reduce hospital placements within the forensic cohort, including ongoing needs relating to forensic risk (Alexander et al., 2015; Chester et al., 2017), and a lack of specialised community service provision (Barnoux, 2019; Washington, Bull, \& Woodrow, 2019). One of the most significant drivers for continued use of inpatient ID services is mental ill health.

Children and adolescents with ID are a group that are especially vulnerable to mental health issues and challenging behaviour ${ }^{1}$. This due to a combination of factors, including psychosocial disadvantage (Emerson \& Hatton, 2007), stigma (Ali, King, Strydom, \& Hassiotis, 2015), bullying (Hatton, Emerson, Robertson, \& Baines, 2018), poor communication skills, sensory disabilities, epilepsy, physical illness and genetic syndromes, effects of medications, abusive experiences and behavioural phenotypes (Allington-Smith, 2006), with some syndromes which cause ID being associated with aggressive behaviour (Powis \& Oliver, 2014). Another factor is the experience of failure, especially in educational settings, in comparison to siblings and similar age peers (Bybee \& Zigler, 1999; Zigler, Bennett-Gates, Hodapp, \& Henrich, 2002). This is in addition to navigating the same myriad challenges and tasks experienced by all young people, without having equal degrees of intellectual ability and social capacity (O'Brien \& Bell, 2004) and a more limited range of coping strategies (Allington-Smith, 2006).

Gralton (2013) highlighted that those with ID appear to be over represented in populations of adolescent offenders. In a survey of 301 young offenders in custodial settings or attending community youth offending teams, approximately $20 \%$ of young offenders had an IQ less than 70 (Chitsabesan et al., 2007). Similar rates were reported in Maryland, United States, with 20\% of the juvenile justice population $(n=376)$ meeting diagnostic criteria for mental retardation

\footnotetext{
${ }^{1}$ In this paper the following definition of challenging behaviour will be employed: "Behaviour can be described as challenging when it is of such an intensity, frequency or duration as to threaten the quality of life and/or the physical safety of the individual or others and is likely to lead to responses that are restrictive, aversive or result in exclusion" (Royal College of Psychiatrists and British Psychological Society and Royal College of Speech and Language Therapists, 2007).
} 
(Shelton, 2006). This is despite the significant under recognition of this group within custodial settings (Ford et al., 2008). Shelton (2006) described the high use of incarceration as a method of control for children with behavioural problems as a "disconnect between society and youth". This causes missed opportunities for prevention, barriers to early childhood services, and a lack of recognition within school, contributing to the "dumping of...youth with troubled and troublesome behaviours into the juvenile justice system” (p. 42).

Elucidating when such mental and behavioural issues arise in children and adolescents with ID could support future service development, in order to ensure that the right services are offered at the right time in the life course, i.e. prior to such behaviour reaching a forensic threshold. Yet minimal research has examined this. One study examined age-related variables of patients admitted to four secure services in the UK; age at first conviction, and age at admission (Alexander, Chester, Gray, \& Snowden, 2012). The study compared these variables between patients with ID alone, personality disorder (PD) alone, and those with comorbid ID and PD. It was found that patients with PD alone were significantly younger at first conviction (aged 16) than those with ID alone, or ID and PD (aged 19). There were no significant differences on the age at admission to forensic services, which was between 25-30 years of age. While these findings provide an indicator of the onset of forensic issues, it is likely that patients' needs will have been evident much earlier. This is an important area of consideration, as recent policy initiatives in the UK are emphasising the importance of early intervention for those with ID and/or challenging behaviour, mental disorders, or forensic issues, in order to reduce the need for inpatient admissions (NHS England, 2015a). This study therefore aims to identify the age at which antisocial and violent behaviour was first observed among a cohort of inpatients within a forensic ID service.

\begin{abstract}
Method

\section{Participants / Setting}

The study took place in a 95-bed inpatient ID forensic service, with medium secure, low secure, and rehabilitation wards, i.e. category 1,4 , and 5 beds in the classification used by the Royal College of Psychiatrists' Faculty of Psychiatry of Intellectual Disability (2013) and the Count me in Census (Health and Social Care Information Centre, 2015). Eighty-four patients were included in the study; 50 men, 33 women, and one patient who identified as transgender (male to female). Forensic ID services typically care for those with an ID level within the mild range, with a minority of patients falling in the borderline, or moderate categories (Chester et al., 2017). The mean age of the patients was 34 (range 18-60).
\end{abstract}

\title{
Measures
}

The Historical Clinical Risk Management-20, Version 3 (HCR-20v3, Douglas, K. S., Hart, Webster, \& Belfrage, 2013).

The HCR $-20^{\mathrm{V} 3}$ is a structured clinical judgment tool whereby the clinician is systemically guided through a series of risk factors that they must decide which are present or absent for any patient being assessed. The tool is widely accepted as the instrument of choice for predicting future violence within forensic populations, and studies have validated its use in ID populations 
(Fitzgerald, Gray, Taylor, \& Snowden, 2011; Gray, Fitzgerald, Taylor, MacCulloch, \& Snowden, 2007). The HCR-20 $2 \mathrm{~V}^{3}$ is divided into 10 items related to historical factors (e.g., past history of mental illness), 5 items related to current clinical presentation (e.g., current symptoms of major mental illness) and 5 items related to future risk factors (e.g., noncompliance with remediation attempts) (Judges, Egan, \& Broad, 2016). A summary of HCR$20^{\mathrm{V} 3}$ items is provided in Table 1 . Each item is scored as 0 (not present), 1 (partially present) or 2 (present), leading to a maximum total score of 40 . Clinicians also provide qualitative information as to the evidence that informed their decision for the numerical score. The HCR$20^{\mathrm{V} 3}$ assessment is based upon the evaluator assembling a sufficient information base upon which to make ratings of risk factors, and why they have led a person to be violent, which typically involves an interview with the patient being evaluated, plus a review of case files (Douglas et al., 2014). A number of studies have investigated the predictive validity of the HCR-20 in ID populations in regards to institutional aggression (Chaplin, Eyeoyibo, Wright, Xenitidis, \& McCarthy, 2015; Fitzgerald et al., 2013; O'Shea, Picchioni, McCarthy, Mason, \& Dickens, 2015) and future reconviction (Gray et al., 2007), and reported equivalent, or higher levels of validity in the ID population as compared to the general forensic population.

This measure was chosen for the study due to its inclusion of age data within the scores and qualitative evidence provided for two items; H1 History of Problems with Violence and H2 History of Problems with Other Antisocial Behaviour. For H1, the threshold of behaviour scored includes any actual, attempted of threatened harm of another person, incorporating arson and sexual offences. $\mathrm{H} 2$ captures any actual, attempted or planned violation of the rights, safety, or well-being of others that violate social norms. Examples include plans motivated by financial or material gain, gang, or substance related activity. On these items the clinician is also asked to score the presence, partial presence, or absence of the behaviour at different time points; as a Child (12 and under), as an Adolescent (13 - 17) and as an Adult (18 and over), which can indicate the time behaviours were first observed during the patient's life.

Table 1: Summary of HCR $-20^{V 3}$ items.

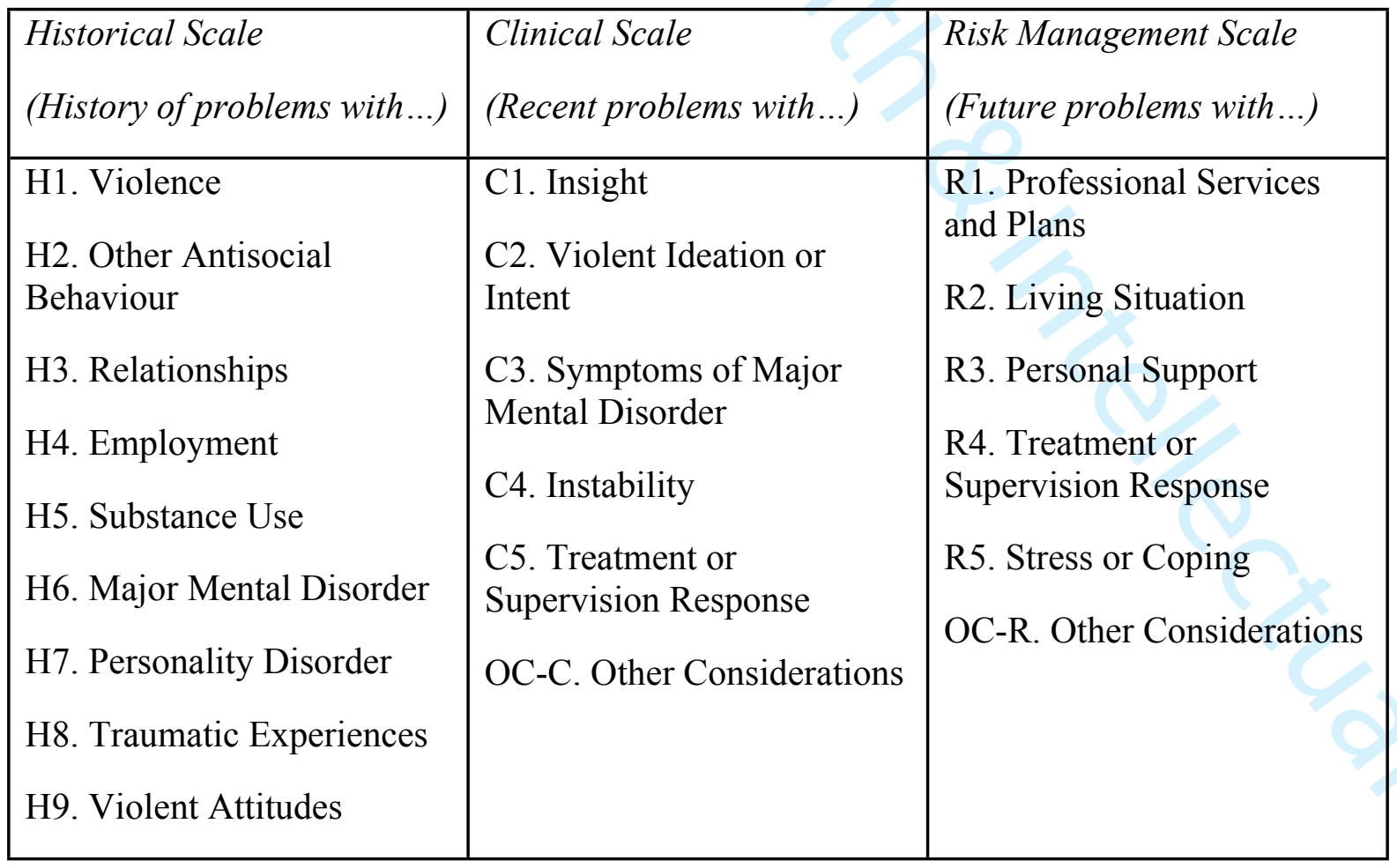


H10. Treatment or Supervision Response

OC-H. Other Considerations

\section{Procedure}

HCR-20 $2 \mathrm{~V}^{3}$ data pertaining to each patient was aggregated, then anonymised, by removing any patient identifiable information, in accordance with the Data Protection Act (Her Majesty's Government, 1998) and the General Data Protection Regulation (Information Commissioners Office, 2018).

\section{Analysis}

Descriptive statistics are provided at the group level, to include the number and percentage of patients which scored as present, partially present or absent on the two items of interest on the HCR-20 V3 and their sub-categories. The mean age values, and age ranges within each item subcategory, are also provided.

\section{Ethical Considerations}

The study utilised data from assessments that are routinely competed with the service. Informed consent is gained from patients prior to assessments completion. In accordance with NHS guidance (Health Research Authority, 2017), the project fulfilled criteria for service evaluation and as such did not require approval from a NHS Research Ethics Committee.

\section{Results}

Item H1, History of Problems with Violence, was scored as present for all 84 patients. As detailed in Table 1, of this group, 38 (45\%) first had problems documented as a child, $24(29 \%)$ as an adolescent, with the remaining $22(26 \%)$ whose problems were first documented in adulthood. The average age of the child subgroup was 8 years, while the youngest of this group was 2 years of age.

Item H2, History of Problems with Other Antisocial Behaviour, was scored as present for 47 $(56 \%)$ of patients, as partial for $20(24 \%)$ patients, and as absent for $17(20 \%)$ patients. Of the 67 patients who were scored as present or partially present, for 26 patients (39\%) problems were first documented when the patient was a child, $24(36 \%)$ as an adolescent, and $17(25 \%)$ as an adult. The average age of the child subgroup was 9 years, while the youngest of this group was 4 years of age. For a graphical representation of this data, please see Figure 1.

Table 1: Age problems with violence or other antisocial behaviour were first documented

\begin{tabular}{|c|l|c|c|c|c|}
\hline \multirow{2}{*}{ Item } & & \multirow{2}{*}{$\mathbf{n}$} & \multirow{2}{*}{$\%$} & \multicolumn{2}{|c|}{ Exact age } \\
\cline { 5 - 6 } & & & & Mean & Range \\
\hline \multirow{2}{*}{$\mathrm{H} 1 \uparrow$} & As a child $(12$ and under) & 38 & 45 & 8 & $2-12$ \\
\cline { 2 - 6 } & As an Adolescent $(13-17)$ & 24 & 29 & 15 & $13-17$ \\
\hline
\end{tabular}


Figure 1: Age problems with violence or other antisocial behaviour were first documented

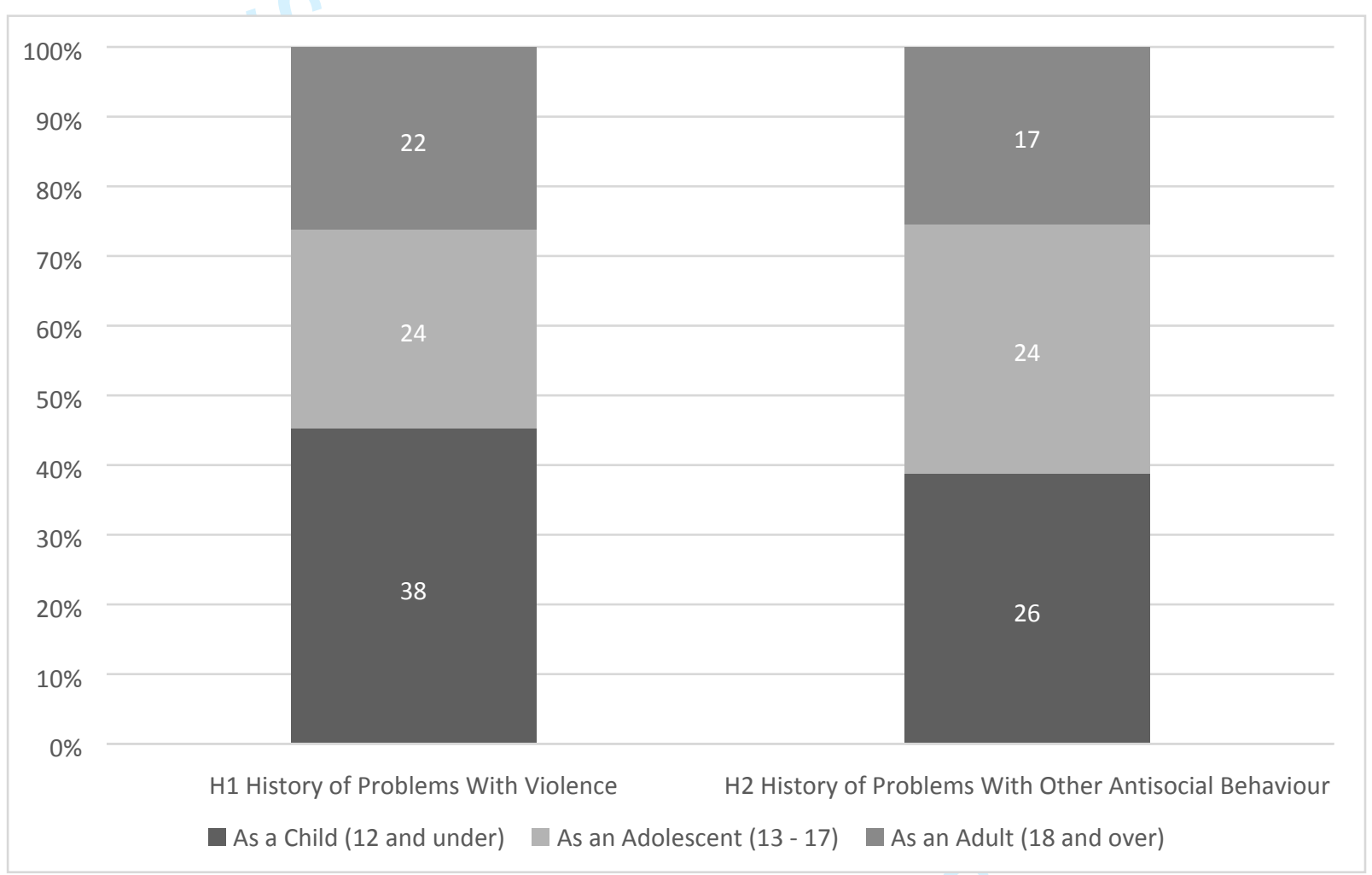

\section{Discussion}

This study examined the age at which antisocial or violent behaviour was first exhibited by patients detained in a forensic ID service, reporting that, for the majority of individuals, this was first observed in childhood or adolescence. This is an important finding, as individuals who present with an early onset of anti-social behaviour typically persist with such behaviour through adolescence and adulthood, and the seriousness of behaviour escalates over time (Moffitt, Caspi, Harrington, \& Milne, 2002). This group is responsible for a disproportionate amount of violent and sexual offending in adulthood (Moffitt et al., 2002). Furthermore, this finding suggests that early intervention services could have a role in targeting factors which could reduce future offending, and improve outcomes in this population (Newman, Talbot, Catchpole, \& Russell, 2013). While this pattern is similar to the offending profiles of those without ID, these findings are of particular concern since services for this population are comparatively under resourced, despite the disproportionate risk of mental health (Sin, Francis, $\&$ Cook, 2010), challenging behaviour, and forensic issues. 
Therefore, those with ID presenting in childhood and adolescence with antisocial and / or violent behaviour need to be prioritised for access to services. Two models of mental health service delivery are available for children with ID; the Child and Adolescent Mental Health Service (CAMHS), or the community ID team for children and adolescents (Gangadharan, Bretherton, \& Johnson, 2001). However, this means that this group can fall between the gaps of these two services (Gangadharan et al., 2001). Until 30 years ago, a major component of lifespan ID services was a mental health service for young people, however this assistance is now considerably reduced (The Royal College of Psychiatrists, 2016). When accessing generic CAMHS, those with ID are less likely to have their psychiatric and developmental needs recognised, understood and addressed in an evidence-based and optimally therapeutic fashion, largely due to a lack of specialised expertise and resources required to provide comprehensive assessments and ongoing management (Bernard \& Turk, 2009; Gralton, 2013). A third option is a dedicated ID service, with trained staff and clinicians, integrated into the Child and Adolescent Mental Health service (CAMHS-ID) (Gangadharan et al., 2001). Within the present organisation of CAMHS, ID services may fall under "Tier 4 Specialised CAMHS" defined as "day and inpatient services and some highly specialist outpatient services" (NHS England, 2014, p. 11).

Within Tier 4, a limited number of secure / forensic adolescent hospitals are available, in six regions of England (Hill, Chamorro, Hosking, \& Ferreira, 2018). These services are classed as medium-secure psychiatric care but provide care for young people with the highest risks, whose adult equivalents would be managed in high secure hospitals such as Broadmoor, Ashworth and Rampton (Hill et al., 2018). The authors noted that only one of the six services is specialised children and adolescents with ID, although one of the 100 patients included in this study was noted to have an ID. Furthermore, a number of harmful sexual behaviour teams for children or young people under the age of 18 exist, although these teams have not been extensively researched (Almond \& Giles, 2008). As such, the availability of CAMH services is highly variable across the UK, and admissions are affected by the interaction of age, geography, sub-specialty (e.g. a lack of low or medium secure CAMHS-ID provision) (NHS England, 2014). There is a particular lack of outcome research for those with ID who have received input from the spectrum of available CAMH services.

Where appropriate, the admission of young people with mental health problems to specialist inpatient units has been shown to be clinically and cost-effective, associated with substantive improvements across a range of diagnoses (Green et al., 2007). Chaplin, Roach, Johnson and Thompson (2015) investigated the outcomes of 113 children and adolescents with and without ID admitted to one of $14 \mathrm{CAMH}$ services. The authors reported improved clinical outcomes amongst both groups, while noting that the ID group had longer lengths of stay. While such services are associated with improved outcomes, their availability is patchy, and they cover very large geographical areas, which negatively affects transitional support arrangements (NHS England, 2014). It was noted that these beds tend to focus on young people with moderate to severe levels of ID, which might suggest that those with milder levels of ID are seen by mainstream CAMHS. Few studies have examined the outcomes from secure CAMHS (Johnston \& Gowers, 2005), and no studies have reported the outcomes of those with ID treated in such services. Hill, Chamorro, Hosking and Ferreira (2018) examined the demographic, clinical and personality characteristics of first 100 patients consecutively admitted to and discharged from an NHS mixed-gender secure hospital for adolescents in the UK. In this cohort, females had a higher average length of stay, and higher rates of incidents than males, which the authors felt reflected the females' high rates of enduring personality-related 
problems. Incident rates and childhood abuse were highly correlated, suggesting that a history of childhood abuse is a potent risk factor for self-harm and aggression.

The findings of the present study also have implications regarding the availability and efficacy of treatment within CAMH services. Cooper et al. (2014) noted the benefits of providing evidence-based behavioural interventions and doing so early, and that approaches that work well with children generally are also likely to be effective for children with ID. Depending on the needs of the individual child or adolescent, there are several promising care models for those exhibiting such issues in childhood and adolescence. These include parenting programmes, training and support for families, and positive behavioural support (PBS) (Cooper et al., 2014), as well as respite and therapeutic interventions (Reid, Sholl, \& Gore, 2013; Sholl, Reid, \& Udwin, 2014). Reid et al. (2013) described an intensive therapeutic and short break service for young people at risk of entering residential placements in early adolescence due to challenging behaviour that had become too difficult for families and schools to manage. The service is a collaboration between health and social care, and provides a combination of interventions according to the individual needs of the child or adolescent, including PBS, systemic approaches, therapeutic interventions, such as cognitive behaviour therapy, and short breaks. An evaluation highlighted reduced behavioural difficulties and a decrease in parental concerns.

The availability and uptake of individualised psychological therapy for children and adolescents with ID, challenging behaviour, mental disorders, or forensic issues is unknown. However, such therapies are only accessible through secondary care services or private practice, and therefore an individual child or adolescent would first need to access an appropriate secondary care service. A survey completed in 2006 reported that only $72 \%$ of cases were receiving psychological therapy in a South London CAMHS, in contravention of the 100\% target detailed in relevant NICE guidelines (Perera, Gupta, Samuel, \& Berg, 2007).

For early interventions to be successful, they should be offered systematically, as a result of regular screening of those at risk of challenging behaviour (Cooper et al., 2014). Interventions should recognise the multifactorial causes of challenging behaviour (including physical/mental health issues, social circumstances, communication). Input should be continued, rather than requiring referral and re-referral. Approaches should be based on PBS frameworks, and be family centred. These should be offered in accordance with relevant National Institute for Health and Care Excellence (NICE) guidelines, e.g. those for ID and challenging behaviour (NICE, 2018; NICE, 2015), as well as those with antisocial behaviour and conduct disorders (NICE, 2013).

Guidelines have been developed for young people at risk of coming into contact with the youth justice system (NHS England, 2014). These state that children and adolescents should have access to the same preventative initiatives aimed at reducing behaviours that may lead to contact with the law as the adult population. This should include parenting programmes, liaison and diversion, troubled family schemes, gang services and youth offending teams. Services should have processes in place to identify young people with ID, and to make reasonable adjustments. This should be achieved through collaboration with and support from specialist multi-disciplinary health and social care services. Children and young people with ID who are known to Youth Justice Services should be identified, enabling proactive service coordination across agencies and ensuring clear pathways from and to different services. In some instances, where there is greatest risk, individuals may be included on a local register to ensure they get the appropriate support. 
While early intervention is advocated, caution has been raised that this group of young people should not face a lifelong future in institutional care (Lenehan, 2017). Prolonged inpatient stays are most likely in areas without fully developed care pathways. Unfortunately, community CAMHS-ID are not well developed in many areas of the country, meaning that further work is required to provide a comprehensive care pathway (NHS England, 2014). These variations have existed for some years and reflect both historical local priorities and uncoordinated growth. Due to this fragmented service development, care is inappropriately shifted to secure social and residential schools, which are often a long geographical distance from the family home (Gralton, 2013). Additionally, there is a negative impact on family life, with an increased likelihood of sibling and parental emotional distress, and family breakdown (Bernard \& Turk, 2009). Furthermore, these placements are high cost, with rates cited as ranging from ranging from $£ 130,291$ to $£ 266,968$ per year for 52 week in 2012 (Sholl et al., 2014), rates which are likely to have increased in the past few years. In practice, many young people remain in out of area residential placements as adults (Department of Health, 2007). Lenehan (2017) therefore recommended that an urgent review is undertaken into the needs of young people aged 18-25 currently in inpatient provision (whether they are in acute inpatient, mental health or learning disability beds), including numbers, routes of admission and destinations to ensure this group of young people do not face a lifelong future in institutional care.

The present study also highlighted a smaller subgroup of participants whose problems with violence or antisocial behaviour were first observed in adulthood. This is an interesting finding, as research suggests that offending behaviour typically emerges in childhood or adolescence. It is possible that this group may have specific clinical or forensic differences, or that their behaviour did not reach the attention of services until adulthood. Indeed, violent or antisocial behaviour can go unrecognised, due to paid carers being less likely to involve the police when an offence is committed by a perpetrator with ID (Clare \& Murphy, 1998; Lyall, Holland, \& Collins, 1995). It could also be due to difficulties arising during the transition from adolescence and adulthood itself, and / or from youth to adult services (Barron \& Hassiotis, 2008).

The study has a number of drawbacks. Firstly, whether the participants in this study received input from early intervention services, and the degree or outcome of this input is unknown. This is because the study utilised routinely collected data from HCR-20 ${ }^{\mathrm{V} 3}$ assessments, and this information is not captured by this tool. However, it is not unreasonable to assume that input for this specific cohort may been limited, given that the first secure psychiatric hospital for adolescents in the United Kingdom opened in 1985 (Hill et al., 2018) and that the average age of patients is 30 at referral and admission (Alexander, Piachaud, Odebiyi, \& Gangadharan, 2002; Alexander et al., 2011). Furthermore, individual patient sociodemographic, clinical, or forensic data was not collated. This could have added depth to the analysis, particularly in regards to providing context on factors which might differentiate patients whose challenging / offending behaviour did not emerge until adulthood, as compared to the rest of the study sample. Furthermore, the validity of the data is dependent on the quality of clinical notes and patient knowledge upon which the HCR-20 $2{ }^{\mathrm{V}}$ was based, and the overall quality of the HCR$20^{\mathrm{V} 3}$ assessment itself. The study is limited further by its lack of a control group without ID. Nevertheless, this relatively simple service evaluation project has a number of practical applications, particularly in the current context of increased focus on ID service provision.

There is a currently a national service model aiming to reduce the need for inpatient care of people with ID, through the strengthening of community service provision, the Transforming Care programme (Department of Health, 2012; NHS England, 2015b). References to child and adolescent mental health services within the strategy are minimal. Similarly, a recent green 
paper on mental health provision for children and young people within educational settings had limited focus on ID (Department of Health \& Department for Education, 2017). Positively, autism, ID, and children and young people's mental health services, are specified as priorities in the NHS Long Term Plan (NHS, 2019), which may afford the opportunity for the development of services. The plan commits to increased investment in intensive, crisis and forensic community support that will enable more people to receive personalised care in the community, closer to home, and reduce preventable admissions to inpatient services. However, Lenehan (2017) cautioned that even when this group are not entirely ignored by government programmes and priorities, the challenge is that everybody's business becomes no-one's priority. This is a missed opportunity, and the famous quote "It's easier to build strong children than repair broken men" by Frederick Douglas resonates. It is therefore recommended that increased attention and focus should be given to this under-recognised population, and that future work examines whether early intervention services for children and adolescents with ID and challenging, or offending behaviour improve outcome the long term outcomes of this marginalised group.

\section{Conclusion}

Evidently, there are a number of patients treated in forensic ID services whose behaviours first arose during childhood and adolescence. It is therefore recommended that this group are prioritised for access to early intervention services. The range of services and pathways is highly variable across the UK, and it is highly likely this affects access to and uptake to appropriate assessment and treatment, as well as the outcomes of individuals within this population. It is therefore recommended that commissioners and providers review the provision of services for children and adolescents with ID, behavioural and / or mental health issues, in order to maximise outcomes, better meet the aims of the Transforming Care programme, and reduce the risk of these individuals becoming the future forensic cohort. Furthermore, research on the models of service and therapy provision with the best short and long term outcomes for this population is urgently required.

\section{References}

Alexander, R., Devapriam, J., Michael, D., McCarthy, J., Chester, V., Rai, R., ... Roy, A. (2015). "Why can't they be in the community?" A policy and practice analysis of transforming care for offenders with intellectual disability. Advances in Mental Health and Intellectual Disabilities, 9(3), 139-148. https://doi.org/10.1108/AMHID-02-20150011

Alexander, R. T., Chester, V., Gray, N. S., \& Snowden, R. J. (2012). Patients with personality disorders and intellectual disability - closer to personality disorders or intellectual disability? A three-way comparison. Journal of Forensic Psychiatry \& Psychology, 23(4), 435-451. https://doi.org/10.1080/14789949.2012.694462

Alexander, R. T., Hiremath, A., Chester, V., Green, F. N., Gunaratna, I. J., \& Hoare, S. (2011). Evaluation of treatment outcomes from a medium secure unit for people with intellectual disability. Advances in Mental Health and Intellectual Disabilities, 5(1), 22 32. https://doi.org/10.5042/amhid.2011.0013

Ali, A., King, M., Strydom, A., \& Hassiotis, A. (2015). Self-reported stigma and symptoms of anxiety and depression in people with intellectual disabilities: Findings from a cross sectional study in England. Journal of Affective Disorders, 187, 224-231. 
https://doi.org/10.1016/j.jad.2015.07.046

Allington-Smith, P. (2006). Mental health of children with learning disabilities. Advances in Psychiatric Treatment, 12(2), 130-138. https://doi.org/10.1192/apt.12.2.130

Almond, L., \& Giles, S. (2008). Young people with harmful sexual behaviour: Do those with learning disabilities form a distinct subgroup? Journal of Sexual Aggression, 14(3), 227239. https://doi.org/10.1080/13552600802304909

Barnoux, M. (2019). Community services and transforming care: reflections and considerations. Tizard Learning Disability Review, 24(1), 33-37. https://doi.org/10.1108/TLDR-12-2018-0034

Barron, D., \& Hassiotis, A. (2008). Good practice in transition services for young people with learning disabilities: a review. Advances in Mental Health and Learning Disabilities, 2(3), 18-22. https://doi.org/10.1108/17530180200800025

BBC One. (2011). Undercover care: the abuse exposed.

Bernard, S., \& Turk, J. (2009). Developing Mental Health Services for Children and Adolescents with Learning Disabilities: A Toolkit for Clinicians. London.

Bybee, J., \& Zigler, E. (1999). Personality Development in Individuals with Mental Retardation. Personality Development in Individuals with Mental Retardation. Cambridge University Press.

Chaplin, E., Eyeoyibo, M., Wright, S., Xenitidis, K., \& McCarthy, J. (2015). Historical and clinical items of the HCR-20 as predictors of risk within an intellectual disability population. Advances in Mental Health and Intellectual Disabilities, 9(2), 62-69. Retrieved from http://www.emeraldinsight.com/doi/pdfplus/10.1108/AMHID-01-20150002

Chaplin, R., Roach, S., Johnson, H., \& Thompson, P. (2015). Inpatient Children and Adolescent Mental Health Services (CAMHS): outcomes of young people with and without intellectual disability. Journal of Intellectual Disability Research, 59(11), 995998. https://doi.org/10.1111/jir.12148

Chester, V., Brown, A. S., Devapriam, J., Axby, S., Hargreaves, C., \& Shankar, R. (2017). Discharging inpatients with intellectual disability from secure to community services: risk assessment and management considerations. Advances in Mental Health and Intellectual Disabilities, 11(3), 98-109. https://doi.org/10.1108/AMHID-01-2017-0003

Chitsabesan, P., Bailey, S., Williams, R., Kroll, L., Kenning, C., \& Talbot, L. (2007). Serious juvenile offenders with and without intellectual disabilities. Journal of Children's Services, 2(4), 4-17.

Clare, I., \& Murphy, G. (1998). Working with offenders or alleged offenders with learning disabilities. In E. Emerson, C. Hatton, J. Bromley, \& A. Caine (Eds.), Clinical Psychology and People with Intellectual Disabilities (pp. 154-176). Chichester: John Wiley and Sons.

Cooper, V., Emerson, E., Glover, G., Gore, N., Hassiotis, A., Hastings, R., ... Shurlock, J. (2014). Early intervention for children with learning disabilities whose behaviours challenge.

Department of Health. (2007). Services for people with learning disability and challenging behaviour or mental health needs.

Department of Health. (2012). Transforming care: A national response to Winterbourne View Hospital. London.

Department of Health, \& Department for Education. (2017). Transforming Children and Young People's Mental Health Provision: a Green Paper.

Douglas, K. S., Hart, S. D., Webster, C. D., \& Belfrage, H. (2013). HCR-20V3: Assessing risk of violence - User guide. Burnaby, Canada: Mental Health, Law, and Policy Institute, Simon Fraser University. 
Douglas, K. S., Hart, S. D., Webster, C. D., Belfrage, H., Guy, L. S., \& Wilson, C. M. (2014). Historical-Clinical-Risk Management-20, Version 3 (HCR-20V3): Development and Overview. International Journal of Forensic Mental Health, 13(2), 93-108.

Emerson, E., \& Hatton, C. (2007). Mental health of children and adolescents with intellectual disabilities in Britain. British Journal of Psychiatry, 191, 493-499. https://doi.org/10.1192/bjp.bp.107.038729

Fitzgerald, S., Gray, N. S., Alexander, R. T., Bagshaw, R., Chesterman, P., Huckle, P., ... Snowden, R. J. (2013). Predicting Institutional Violence in Offenders with Intellectual Disabilities: The Predictive Efficacy of the VRAG and the HCR-20. Journal of Applied Research in Intellectual Disabilities, 26(5), 384-393. https://doi.org/10.1111/jar.12032

Fitzgerald, S., Gray, N. S., Taylor, J., \& Snowden, R. J. (2011). Risk factors for recidivism in offenders with intellectual disabilities. Psychology, Crime \& Law, 17(1), 43-58.

Ford, G., Andrews, R., Booth, A., Dibdin, J., Hardingham, S., \& Kelly, T. P. (2008). Screening for learning disability in an adolescent forensic population. Journal of Forensic Psychiatry \& Psychology, 19(3), 371-381.

Gangadharan, S., Bretherton, K., \& Johnson, B. (2001). Pattern of Referral to a Child Learning Disability Service. The British Journal of Development Disabilities, 47(93), 99-104.

Gralton, E. (2013). Inpatient assessment of young people with developmental disabilities who offend. Advances in Mental Health and Intellectual Disabilities.

Gray, N. S., Fitzgerald, S., Taylor, J., MacCulloch, M. J., \& Snowden, R. J. (2007).

Predicting future reconviction in offenders with intellectual disabilities: The predictive efficacy of VRAG, PCL-SV, and the HCR-20. Psychological Assessment, 19(4), 474 479. https://doi.org/10.1037/1040-3590.19.4.474

Green, J., Jacobs, B., Beecham, J., Dunn, G., Kroll, L., Tobias, C., \& Briskman, J. (2007). Inpatient treatment in child and adolescent psychiatry--a prospective study of health gain and costs. Journal of Child Psychology and Psychiatry, and Allied Disciplines, 48(12), 1259-1267. https://doi.org/10.1111/j.1469-7610.2007.01802.x

Hatton, C., Emerson, E., Robertson, J., \& Baines, S. (2018). The mental health of adolescents with and without mild/moderate intellectual disabilities in England: Secondary analysis of a longitudinal cohort study. Journal of Applied Research in Intellectual Disabilities, 31(5), 768-777. https://doi.org/10.1111/jar.12428

Health and Social Care Information Centre. (2013). Learning Disabilities Census Report. Health and Social Care Information Centre. (2015). Learning Disability Census Report. Health Research Authority. (2017). UK Policy Framework for Health and Social Care Research. London. Retrieved from https://www.hra.nhs.uk/planning-and-improvingresearch/policies-standards-legislation/uk-policy-framework-health-social-care-research/

Her Majesty's Government. (1998). The Data Protection Act. London.

Hill, S. A., Chamorro, V., Hosking, A., \& Ferreira, J. (2018). Characteristics and personality profiles of first 100 patients admitted to a secure forensic adolescent hospital. Journal of Forensic Psychiatry and Psychology.

Hollins, S. (2000). Developmental psychiatry - Insights from learning disability. British Journal of Psychiatry. https://doi.org/10.1192/bjp.177.3.201

Information Commissioners Office. (2018). Guide to the General Data Protection Regulation (GDPR).

J., T., \& Talbot, J. (2009). No One Knows: Offenders with learning disabilities and learning difficulties. International Journal of Prisoner Health, 5(3), 141-152. https://doi.org/10.1080/17449200903115797

Johnston, C., \& Gowers, S. (2005). Routine Outcome Measurement: A Survey of UK Child and Adolescent Mental Health Services. Child and Adolescent Mental Health, 10(3), 
133-139. https://doi.org/10.1111/j.1475-3588.2005.00357.x

Judges, R., Egan, V., \& Broad, G. (2016). A Critique of the Historical Clinical Risk-20, Version 3, Risk Assessment Instrument. Journal of Forensic Psychology Practice, 16(4), 304-320.

Lenehan, C. (2017). These are our children.

Lyall, I., Holland, A. J., \& Collins, S. (1995). Offending by adults with learning disabilities and the attitudes of staff to offending behaviour: implications for service development. Journal of Intellectual Disability Research, 39(6), 501-508.

Moffitt, T. E., Caspi, A., Harrington, H., \& Milne, B. J. (2002). Males on the life-coursepersistent and adolescence-limited antisocial pathways: follow-up at age 26 years. Development and Psychopathology, 14(1), 179-207. Retrieved from http://www.ncbi.nlm.nih.gov/pubmed/11893092

National Audit Office. (2015). Care Services For People With Learning Disabilities and Challenging Behaviour.

National Institute for Clinical Excellence. (2013). Antisocial behaviour and conduct disorders in children and young people: recognition and management.

National Institute for Clinical Excellence. (2018). Learning disabilities and behaviour that challenges: service design and delivery. London.

Newman, R., Talbot, J., Catchpole, R., \& Russell, L. (2013). Turning young lives around: How health and justice services can respond to children with mental health problems and learning disabilities who offend. London.

NHS. (2019). The NHS Long Term Plan. London.

NHS England. (2014). Child and Adolescent Mental Health Services (CAMHS) Tier 4 Report. London.

NHS England. (2015a). Building the right support: A national plan to develop community services and close inpatient facilities for people with a learning disability and/or autism who display behaviour that challenges, including those with a mental health condition. London.

NHS England. (2015b). Supporting people with a learning disability and/or autism who display behaviour that challenges, including those with a mental health condition. Service model for commissioners of health and social care services. London.

O'Brien, G., \& Bell, G. (2004). Learning disability, autism and offending behaviour. In S. Bailey \& M. Dolan (Eds.), Adolescent Forensic Psychiatry.

O’Shea, L. E., Picchioni, M. M., McCarthy, J., Mason, F. L., \& Dickens, G. L. (2015). Predictive validity of the HCR-20 for inpatient aggression: the effect of intellectual disability on accuracy. Journal of Intellectual Disability Research, 59(11), 1042-1054. https://doi.org/10.1111/jir.12184

Perera, A., Gupta, P., Samuel, R., \& Berg, B. (2007). A Survey of Anti-Depressant Prescribing Practice and the Provision of Psychological Therapies in a South London CAMHS from 2003?2006. Child and Adolescent Mental Health, 12(2), 70-72. https://doi.org/10.1111/j.1475-3588.2007.00445.x

Powis, L., \& Oliver, C. (2014). The prevalence of aggression in genetic syndromes: A review. Research in Developmental Disabilities, 35(5), 1051-1071. https://doi.org/10.1016/J.RIDD.2014.01.033

Reid, C., Sholl, C., \& Gore, N. (2013, October 14). Seeking to prevent residential care for young people with intellectual disabilities and challenging behaviour: Examples and early outcomes from the Ealing ITSBS. Tizard Learning Disability Review. https://doi.org/10.1108/TLDR-01-2013-0003

Royal College of Psychiatrists' Faculty of Psychiatry of Intellectual Disability. (2013). People with learning disability and mental health, behavioural or forensic problems: the 
role of in-patient services. Faculty Report (FR/ID/03).

Shelton, D. (2006). A Study of Young Offenders With Learning Disabilities. Journal of Correctional Health Care, 12(1), 36-44. https://doi.org/10.1177/1078345806287573

Sholl, C., Reid, C., \& Udwin, O. (2014). Preventing residential care for young people with intellectual disabilities and challenging behaviours: the development of the Ealing Intensive Therapeutic and Short Breaks Service. In ACAMH Occasional Paper 32: Intellectual Disabilities and Challenging Behaviour.

Sin, C., Francis, R., \& Cook, C. (2010). Access to and experience of child and adolescent mental health services: barriers to children and young people with learning disabilities and their families. Mental Health Review Journal, 15(1), 20-28. https://doi.org/10.5042/mhrj.2010.0199

Taylor, J. L., McKinnon, I., Thorpe, I., \& Gillmer, B. T. (2017). The impact of transforming care on the care and safety of patients with intellectual disabilities and forensic needs. BJPsych Bulletin, 41(4), 205-208. https://doi.org/10.1192/pb.bp.116.055095

The National Institute for Health and Care Excellence (NICE). (2015). Challenging behaviour and learning disabilities: prevention and interventions for people with learning disabilities whose behaviour challenges. Retrieved from https://www.nice.org.uk/guidance/ng11

The Royal College of Psychiatrists. (2016). Psychiatric services for young people with intellectual disabilities.

Washington, F., Bull, S., \& Woodrow, C. (2019). The Transforming Care agenda: admissions and discharges in two English learning disability assessment and treatment units. Tizard Learning Disability Review, 24(1), 24-32. https://doi.org/10.1108/TLDR-04-2018-0012

Zigler, E., Bennett-Gates, D., Hodapp, R., \& Henrich, C. C. (2002). Assessing Personality Traits of Individuals With Mental Retardation. American Journal on Mental Retardation, 107(3), 181. 


\begin{tabular}{|c|c|c|}
\hline & Reviewer Comment & Author Response \\
\hline \multirow[t]{8}{*}{ 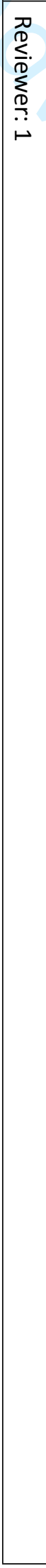 } & $\begin{array}{l}\text { Very interesting paper but limited by amount of data } \\
\text { reported. }\end{array}$ & $\begin{array}{l}\text { Thank you for this } \\
\text { comment. We have } \\
\text { acknowledged the } \\
\text { drawbacks of the data in the } \\
\text { Discussion. }\end{array}$ \\
\hline & $\begin{array}{l}\text { This is an original paper as very little is reported on the HCR- } \\
20 \text { data on those with ID. }\end{array}$ & $\begin{array}{l}\text { Thank you for this } \\
\text { comment. }\end{array}$ \\
\hline & $\begin{array}{l}\text { There is a good reporting of the literature but no reference to } \\
\text { others papers that have looked at the HCR-20 in the ID } \\
\text { population such as: } \\
\text { Predictive validity of the HCR-20 for inpatient aggression: The } \\
\text { effect of intellectual disability on accuracy. (2015). O'Shea L E, } \\
\text { Picchioni M, McCarthy J M, Mason F L, Dickens G L. Journal of } \\
\text { Intellectual Disability Research, } 59 \text { (11), 1042-1054. } \\
\text { Historical and clinical items of the HCR-20 as predictors of risk } \\
\text { with an intellectual disability population (2015). Chaplin E, } \\
\text { Eyeoyibo, S Wright, K, Xenitidis, McCarthy J. Advances in } \\
\text { Mental Health and Intellectual Disability, } 9 \text { (2), 62-69. }\end{array}$ & $\begin{array}{l}\text { I have added the requested } \\
\text { citations alongside previous } \\
\text { research investigating the } \\
\text { HCR-20 into the Method / } \\
\text { Measures section. }\end{array}$ \\
\hline & $\begin{array}{l}\text { This is essentially a descriptive study but would have been } \\
\text { helped if could had matched with a control group without ID. }\end{array}$ & $\begin{array}{l}\text { We have now } \\
\text { acknowledged the lack of a } \\
\text { control group in the } \\
\text { Discussion. We have also } \\
\text { cited comparable literature } \\
\text { in the Discussion (Sin, } \\
\text { Francis, \& Cook, 2010. }\end{array}$ \\
\hline & $\begin{array}{l}\text { There needs to be more information on the study setting such } \\
\text { as were is this secure hospital, does it take a representative } \\
\text { sample of adults with ID etc. }\end{array}$ & $\begin{array}{l}\text { Information on the type of } \\
\text { service is provided under } \\
\text { the Method, Participants / } \\
\text { Setting. }\end{array}$ \\
\hline & $\begin{array}{l}\text { There is no reporting on the level of ID, were they mainly } \\
\text { those in the mild ID group? }\end{array}$ & $\begin{array}{l}\text { We have added information } \\
\text { about the level of ID of the } \\
\text { sample into the Participants } \\
\text { / Setting section. }\end{array}$ \\
\hline & $\begin{array}{l}\text { I think the authors could have looked a little more at the data } \\
\text { available although the numbers may become small but they } \\
\text { could have reported on other H items in the HCR-20 such as } \\
\mathrm{H} 6 \text { that is presence of Major Mental Diorder or not to age of } \\
\text { onset of violent behaviour even if it was a negative finding. }\end{array}$ & $\begin{array}{l}\text { We acknowledge this point } \\
\text { and will focus on it in future } \\
\text { prospective work. As the } \\
\text { primary aim of the study } \\
\text { was to identify the age at } \\
\text { which antisocial and violent } \\
\text { behaviour was first } \\
\text { observed among the study } \\
\text { population, we limited the } \\
\text { analysis to items which } \\
\text { included age data. }\end{array}$ \\
\hline & $\begin{array}{l}\text { The results are clearly presented but not sure why need Figure } \\
1 \text { as saying the same as in Table } 1 .\end{array}$ & $\begin{array}{l}\text { While the figure / table do } \\
\text { contain similar information, }\end{array}$ \\
\hline
\end{tabular}




\begin{tabular}{|c|c|c|}
\hline \multirow[t]{4}{*}{0} & & $\begin{array}{l}\text { one is written and the other } \\
\text { is graphical / illustrative. }\end{array}$ \\
\hline & $\begin{array}{l}\text { The paper does go into detail about practical implications but } \\
\text { little on research implications. }\end{array}$ & $\begin{array}{l}\text { A conclusion has been } \\
\text { added which includes } \\
\text { research implications. }\end{array}$ \\
\hline & $\begin{array}{l}\text { The discussion does tie in with the findings but could have } \\
\text { been more succinct in saying that those with ID presenting in } \\
\text { childhood \& adolescence with violent behaviour need to be } \\
\text { prioritised as a group for CAMH services. Most probably go to } \\
\text { residential school. }\end{array}$ & $\begin{array}{l}\text { This point has been added } \\
\text { to the beginning of } \\
\text { Paragraph } 2 \text { in the } \\
\text { Discussion. }\end{array}$ \\
\hline & Clearly written paper with not too much jargon. & $\begin{array}{l}\text { Thank you for this } \\
\text { comment. }\end{array}$ \\
\hline \multirow{8}{*}{ 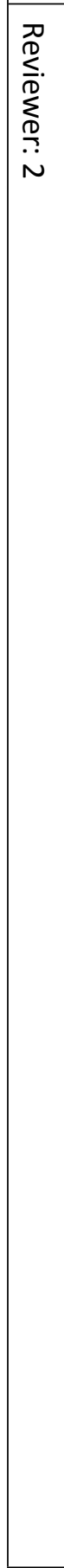 } & $\begin{array}{l}\text { Interesting read which I found engaging and very clinically } \\
\text { relevant. }\end{array}$ & $\begin{array}{l}\text { Thank you for this } \\
\text { comment. }\end{array}$ \\
\hline & $\begin{array}{l}\text { Yes this paper adds to the existing evidence base of which } \\
\text { actual data relating to this client group and particular question } \\
\text { is scarce or non existent. } \\
\text { This paper is also very topical at present given both the } \\
\text { Winterbourne information and transforming care agenda. } \\
\text { Moreover there was another recent BBC documentary on a } \\
\text { similar par to Winterbourne which highlights that these issues } \\
\text { are still very much present and so understanding this area } \\
\text { more and then highlighting potential targets for intervention } \\
\text { is warranted. }\end{array}$ & $\begin{array}{l}\text { Thank you for this } \\
\text { comment. }\end{array}$ \\
\hline & $\begin{array}{l}\text { As mentioned above- this paper highlights existing research in } \\
\text { the field - which is currently limited along with the } \\
\text { transforming care approach as well as Winterbourne - covers } \\
\text { relevant information in a succinct and concise way presented } \\
\text { in a way I found both engaging and interesting to read. }\end{array}$ & $\begin{array}{l}\text { Thank you for this } \\
\text { comment. }\end{array}$ \\
\hline & $\begin{array}{l}\text { I wonder whether a link to the HCR20 could be made if } \\
\text { possible within the introduction with justification for its use } \\
\text { etc- quite clearly apparently done in the method but I wonder } \\
\text { given that it a focal point of this study if it could be weaved in? }\end{array}$ & $\begin{array}{l}\text { We have added a sentence } \\
\text { describing the justification } \\
\text { for the use of the HCR-20 } \\
\text { within the Measures section } \\
\text { of the Method. Due to word } \\
\text { count constrictions, and to } \\
\text { avoid duplications, we have } \\
\text { contained the choice of } \\
\text { measure within the } \\
\text { Method. }\end{array}$ \\
\hline & $\begin{array}{l}\text { Methods employed appear appropriate. Analysis is simple and } \\
\text { clear to follow and understand. }\end{array}$ & $\begin{array}{l}\text { Thank you for this } \\
\text { comment. }\end{array}$ \\
\hline & $\begin{array}{l}\text { Data collected fulfilled criteria as part of service evaluation } \\
\text { however worth highlighting that client consent had been } \\
\text { gained for these assessments initially. }\end{array}$ & $\begin{array}{l}\text { This has now been stated in } \\
\text { the Ethics section within the } \\
\text { Method. }\end{array}$ \\
\hline & $\begin{array}{l}\text { Results are easy to read as clearly presented with the aid of } \\
\text { graphical and tabulated representation which is helpful. }\end{array}$ & $\begin{array}{l}\text { Thank you for this } \\
\text { comment. }\end{array}$ \\
\hline & $\begin{array}{l}\text { The conclusions appear to link with other elements of the } \\
\text { paper. Although some reference could be provided to CAMHS } \\
\text { services with a forensic element for example sexually harmful }\end{array}$ & $\begin{array}{l}\text { Details of forensic and } \\
\text { sexually harmful behaviour } \\
\text { teams has been added to }\end{array}$ \\
\hline
\end{tabular}




\begin{abstract}
behaviour teams and reference to where this would fit in given the research findings.

I also think additional emphasis to the Alexander et al study in the discussion would be beneficial for the reader given that this is one of the rare existing studies available. these findings perhaps in line with individual therapy for example would make a useful addition. Implications of the research are stated and the basics covered, if word limit allows then more depth and consideration of the implications for individual therapy and tailoring it accordingly would reinforce the strength of the proposed argument and associated findings.
\end{abstract}

Clearly written, accessible and an engaging and clinically relevant read! Concise and makes points succinctly.

Would adopt use of behaviours of concern or which may be deemed as challenging in terms of the terminology instead of challenging behaviour.

key words- should offending behaviour be considered here and HCR-20
Paragraph 3 in the Discussion.

The Alexander studies focuses on the characteristics and outcomes of adults with ID in forensic services, however further narrative has been added elsewhere in the Discussion.

We have rephrased the section on therapy to make more clear that this research has implications in that area. We have also added further detail about the need for tailored therapy to be available to improve clinical outcomes. Thank you for this comment.

We have retained the use of the term challenging behaviour in order to align with cited papers and reports, but we have provided a widely accepted definition as a footnote in the introduction.

The HCR-20 keyword has been added. Offending behaviour is captured within the title, and would be captured within most literature searches via this route. 